\title{
Efficacy of Complementary and Alternative Therapies in Cancer Patients: A Systematic Review
}

\author{
Mehrnaz Keramatikerman* \\ Postgraduate Student in Master of Science in Nursing (Medical Surgical), Tehran University of Medical Sciences (TUMS), \\ Department of Nursing and Midwifery, Tehran, Iran
}

*Corresponding author: Mehrnaz Keramatikerman, Tehran University of Medical Sciences, School of Nursing and Midwifery,

Tohid Sq., Tehran 141118, Iran

ARTICLE INFO

Received: 彗 July 13, 2020

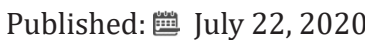

Citation: Mehrnaz Keramatikerman. Efficacy of Complementary and Alternative Therapies in Cancer Patients: A Systematic Review. Biomed J Sci \& Tech Res 29(1)2020. BJSTR. MS.ID.004744.

Keywords: Complementary Therapy; Alternative Therapy; cancer patients; Systematic Review
ABSTRACT

Objective: Complementary and alternative therapies (CATs) are common practices in cancer treatments. This study aims to investigate the most common types of CATs amongst cancer patients and distinguish the most effective practices amongst cancer patients.

Materials and Methods: A comprehensive systematic review was conducted on databases encompass the Science Direct, Cochrane Library, PubMed, EMBASE, Chinese Biomedical Literature Database by following the strategy of Cochrane Collaborative Group. The analysis conducted to investigate efficacy of different complementary and alternative therapies such as acupuncture, herbal medicine, Reiki, and Yoga.

Results and Analysis: The analysis of the different articles from various databases showed that some of the CATs were amongst the most effective methods for cancer patient treatment. The results showed that the herbal medicine was one of the most effective intervention methods and acupuncture was one of the most effective noninterventional methods.

Conclusion: The analysis showed thatapplication of complementary and alternative therapies is effective to improve the symptoms such as pain and depression in patients with cancers in comparison with the conventional therapy. It is recommended that the results to be confirmed with a higher number of samples.

\section{Introduction}

Generally, complementary therapy and alternative medicine (CAM) is applied to cancer patients to alleviate chemotherapy adverse effects and to improve quality of life of these types of patients [1]. CAM treatments have been common amongst cancer patients over years. The use of CAM treatments for cancer patients is varied in the range of $30 \%$ to $90 \%$ in different countries. In Europe, this varies from up to $86 \%$, however, many of these studies are limited to only breast cancer patients. Majority of people who are suffering from cancer believe that using CAM treatments ease the diseases symptoms and improve their health [2-4]. In General, more than $60 \%$ cancer survivors used spiritual practice, around $44 \%$ used relaxation method, around $42 \%$ used spiritual healing, around $40 \%$ used nutritional supplements/vitamins, around $15 \%$ meditation, around $11 \%$ used religious counselling, around $11 \%$ used massage, and around 10\% used support group to treat this disease [5]. The National Centre for Complementary and Integrative Health has categorized CAM in three groups: Mind practice (such as meditation, yoga, massage therapy...), natural products (herbal medicine, probiotics...) and other complementary therapies (homeopathy, Chinese traditional medicine).

The CAM treatments provide better emotional and psychological support in cancer treatment process [6]. The cancer patients are introduced to various types of CAMs through their relatives and friends, they express using CAMs will reduce pain, enhance body immunity system, and encourage them to cope with the diseases [7]. Some patients believed that CAMs are more effective than 
conventional treatments [8]. This study aims to investigate efficacy of the CAMs treatments on cancer patients by performing a comprehensive systematic review study.

\section{Materials and Methods}

A comprehensive systematic review conducted to investigate efficacy of the complementary and alternative medicine therapies (CAMs) on cancer patients. The systematic review followed in this study already described in study performed by the author [9]. Therefore, systematic review was conducted on databases encompass the Science Direct, Cochrane Library, PubMed, EMBASE, Chinese Biomedical Literature Database by following the strategy of Cochrane Collaborative Group. The analysis conducted to investigate efficacy of different complementary and alternative therapies such as acupuncture, herbal medicine, Reiki, and Yoga. (Figure 1) shows a diagram of the most important methods of CAMs in treatment of the cancer patients.

\section{CAM Treatments for Cancer Patients}

This section investigates some of the most common methods that are known as complementary and alternative medicine treatments. This is worth to mention that not all methods mentioned in the (Figure 1) investigated in this section as some of them still need more interrogation in the literature.

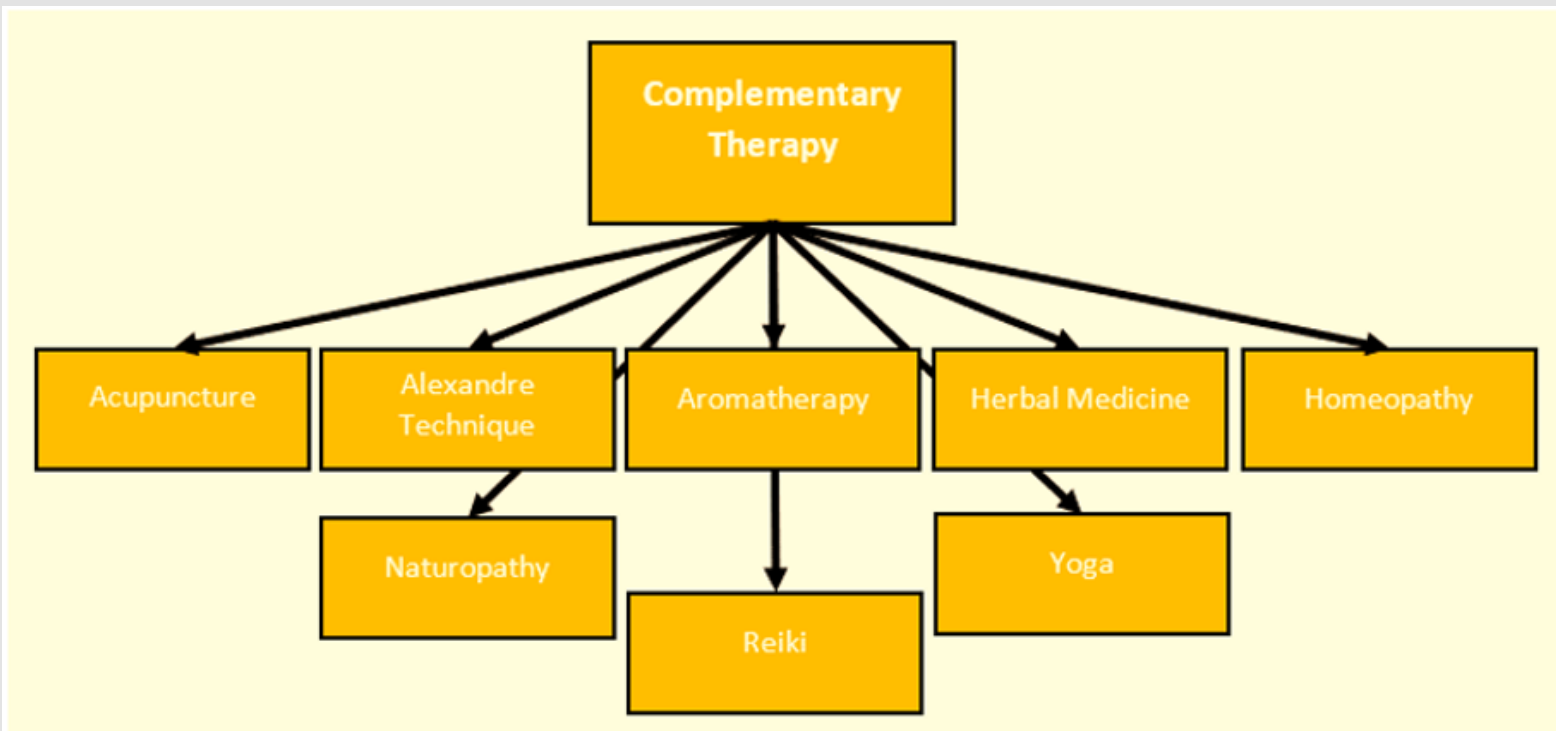

Figure 1: Some of the most popular types of complementary therapy methods.

\section{Acupuncture}

Acupuncture is one of the oldest traditional Chinese medicine which had been used recently worldwide by chronic diseases populations [10], however, one study showed that Acupuncture was not sufficiently effective without drug in cancer pain management while it increases pain remission rate when medicine was used [11]. Another study indicated that abdominal acupuncture can be effective in cancer relate-anorexia [12]. The other study showed that the acupuncture therapy improved the condition of breast cancer-related lymphedema in $95 \%$ of studied population [13].

\section{Aromatherapy}

One study has shown that the aromatherapy is able to enhance psychological and physical complications of more than 3000 cancer patients from 1995 to 2019 [14]. It has also indicated that this method improved sleep quality by smelling Rosa damascena essential oil in patients [15]. Another study showed that aromatherapy alleviated anxiety in stem cell infusion [16]. Also, another study showed that chemotherapy-induced nausea was reduced after Ginger aromatherapy but there was no significant effect on vomiting [17].

\section{Herbal Medicine}

The Medicinal plants are easy to use as herbal medicine which are provided mostly by traditional practitioners and previous successful experience encourage them to use along with chemotherapy [18]. A study about Chinese herbal medicine (CHM) showed that the number of survivals in gastric cancer has improved by using herbal medicine [19]. The traditional herbal medicine also eases peripheral neuropathy and improved immune functions in vitro and in vivo [18]. Also, one study showed that the Oral mucositis severity decreased after using Mille folium along routine solutions [20].

\section{Homeopathy}

The homeopathic treatments action mechanism considered unclear although it is thought to trigger self-regulatory responses [21]. The other study indicated that quality of life in patients receiving homeopathic remedies are as well as patients undergoing conventional treatment [22]. Another study indicated that patients receiving homeopathy treatment along with other remedies are supposed to live longer than the patients who are under conventional chemotherapy [23]. 


\section{Reflexology}

The reflexology action mechanisms are probably based on energy channels theory, lactic acid theory, and neuromatrix pain theory [24]. A study indicated that self-foot reflexology can decrease peripheral neuropathy during chemotherapy, even though it is difficult to explain how it works $[25,26]$. This therapy is also used as palliative care as long as it is non-invasive and relaxing for endstage cancer patients [27]. There are also some unwanted effects such as fatigue, swelling and urination frequency at the application site [24].

\section{Result and Discussion}

Many cancer patients are interested in relaxation as they can relieve physiological and psychological tension during receiving treatments. Herbal medicine popularity is mostly due to alleviation of chemotherapy adverse effects. Other CAM method types are not widely used and known by patients. The main reason of using any kind of CAM for cancer patients is mostly to improve quality of life and palliative care and ease the probable effects which can impact the lives of cancer patients. The modern chemotherapies are primary treatments for many cancers. CAMs would be applied along with conventional remedies unless the patients refuse. However, CAM is not commonly used as worldwide, and many patients are not introduced to other treatments. Few Complementary therapies protocols have been practiced and recommended to hospitals for chemotherapy applicants, in order to diminish side effects.

\section{Conclusion}

A comprehensive systematic review conducted to investigate efficacy of the complementary and alternative medicines (CAMs) on cancer patients. Various CAMs treatments were investigated, and it was revealed that the herbal therapy is a common and amongst the most effective methods to improve quality of lives of the cancer patients. Also, it was revealed that the acupuncture is amongst the most common types of the non-interventional CAM treatment methods. Some CAM methods still would require more investigations and studies in order to judge their performance on cancer patients. CAM treatments have been recognized as one part of helpful cancer treatments. It also supports patients physically and mentally to cope with diseases and ease the pain. CAM types usage is varied based on the religion, age, culture, and other effective factors among countries. Despite the significant role of alternative medicine, some patients are acquainted with other treatments and few of them apply theses remedies to ease the situation. Health care providers play a key role to introduce CAMs categories to end stage patients as one of the choices of palliative care.

\section{References}

1. (2002) National Cholesterol Education Program (US). Expert Panel on Detection, Treatment of High Blood Cholesterol in Adults. Third report of the National Cholesterol Education Program (NCEP) Expert Panel on detection, evaluation, and treatment of high blood cholesterol in adults (Adult Treatment Panel III). National Cholesterol Education Program, National Heart, Lung, and Blood Institute, National Institutes of Health.
2. Bener A, Zirie M, Janahi IM, Al Hamaq A0, Musallam M, et al. (2009) Prevalence of diagnosed and undiagnosed diabetes mellitus and its risk factors in a population-based study of Qatar. Diabetes research and clinical practice 84(1): 99-106.

3. Bener A, Zirie M, Musallam M, Khader YS, Al Hamaq AOAA (2009) Prevalence of metabolic syndrome according to adult treatment panel III and international diabetes federation criteria: A population-based study. Metabolic Syndrome and Related Disorders 7(3): 221-230.

4. Brunzell JD, Davidson M, Furberg CD, Ronald B Goldberg, Barbara V Howard, et al. (2008) Lipoprotein management in patients with cardiometabolic risk: Consensus statement from the American diabetes association and the American college of cardiology foundation. Diabetes Care 31(4): 811-822.

5. Bener A, Dafeeah E, Ghuloum S, Al Hamaq AOAA (2012) Association between psychological distress and gastrointestinal symptoms in type 2 diabetes mellitus. World Journal of Diabetes 3(6): 123-129.

6. Charlesworth E, Hughes J, Plant H, Carballo L (2018) Complementary therapy for people with cancer; the patient's perspective. European Journal of Integrative Medicine 17: 26-32.

7. Abdalla ME, Ali AM, Loong L (2020) The use of complementary and alternative medicine (CAM) among cancer patients at a tertiary hospital in Malaysia. Complementary Therapies in Medicine 50: 102343.

8. Toygar İ, Yeşilbalkan ÖU, Kürkütlü M, Aslan A (2020) Complementary and alternative medicines used by cancer patients to cope with chemotherapy-induced constipation. Complementary Therapies in Clinical Practice 39: 101108.

9. Keramatikerman M. A Systematic Review on Challenges Faced by Family. Caregivers of Cancer Patients. 2020 - 2(4) OAJBS.ID.000191. DOI: 10.38125/OAJBS.000191

10. Vander Ploeg K, Yi X (2009) Acupuncture in modern society. Journal of acupuncture and meridian studies 2(1): 26-33.

11. Hu C, Zhang H, Wu W, Yu W, Li Y, et al. (2016) Acupuncture for pain management in cancer: A systematic review and meta-analysis. Evidence-Based Complementary and Alternative Medicine 2016.

12. Lu WA, Yingying WA (2019) Abdominal acupuncture combined with megestrol acetate for advanced cancer-related anorexia: A randomized controlled trial. World Journal of Acupuncture-Moxibustion 29(3): 200205 .

13. Shibo YU, Lizhe ZH, Peiling XI, JIANG S, Zongbo YA, et al. (2019) Effects of Acupuncture on Breast Cancer-Related Lymphoedema: A Systematic Review and Meta-Analysis. EXPLORE.

14. Farahani MA, Afsargharehbagh R, Marandi F, Moradi M, Hashemi SM, et al. (2019) Effect of aromatherapy on cancer complications: A systematic review. Complementary therapies in medicine 47: 102169.

15. Heydarirad G, Keyhanmehr AS, Mofid B, Nikfarjad H, Mosavat SH (2019) Efficacy of aromatherapy with Rosa damascena in the improvement of sleep quality of cancer patients: A randomized controlled clinical trial. Complementary therapies in clinical practice 35: 57-61.

16. Izgu N, Yayla EM, Ozdemir L, Gemalmaz A (2020) Inhalation Aromatherapy on Nausea, Vomiting and Anxiety during Autologous Hematopoietic Stem Cell Transplantation: An Open-Label Randomized Controlled Trial. European Journal of Integrative Medicine 4: 101091.

17. Lua PL, Salihah N, Mazlan N (2015) Effects of inhaled ginger aromatherapy on chemotherapy-induced nausea and vomiting and health-related quality of life in women with breast cancer. Complementary therapies in medicine 23(3): 396-404.

18. Kim W, Lee WB, Lee JW, Min BI, Baek SK, et al. (2015) Traditional herbal medicine as adjunctive therapy for breast cancer: A systematic review. Complementary therapies in medicine 23(4): 626-632.

19. Hung KF, Hsu CP, Chiang JH, Lin HJ, Kuo YT, et al. (2017) Complementary Chinese herbal medicine therapy improves survival of patients with gastric cancer in Taiwan: A nationwide retrospective matched-cohort 
study. Journal of ethnopharmacology 199: 168-174.

20. Miranzadeh S, Adib Hajbaghery M, Soleymanpoor L, Ehsani M (2015) Effect of adding the herb Achillea millefolium on mouthwash on chemotherapy induced oral mucositis in cancer patients: A double-blind randomized controlled trial. European Journal of Oncology Nursing 19(3): 207-213.

21. Milazzo S, Russell N, Ernst E (2006) Efficacy of homeopathic therapy in cancer treatment. European Journal of Cancer 42(3): 282-289.

22. Guethlin C, Walach H, Naumann J, Bartsch HH, Rostock M (2010) Characteristics of cancer patients using homeopathy compared with those in conventional care: A cross-sectional study. Annals of Oncology 21(5): 1094-1099.

23. Gaertner K, Müllner M, Friehs H, Schuster E, Marosi C, et al. (2014) Additive homeopathy in cancer patients: Retrospective survival data from a homeopathic outpatient unit at the Medical University of Vienna. Complementary therapies in medicine 22(2): 320-332.

ISSN: 2574-1241

DOI: 10.26717/BJSTR.2020.29.004744

Mehrnaz Keramatikerman. Biomed J Sci \& Tech Res

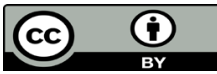

This work is licensed under Creative Commons Attribution 4.0 License

Submission Link: https://biomedres.us/submit-manuscript.php
24. Unlu A, Kirca 0, Ozdogan M (2018) Reflexology, and cancer. Journal of Oncological Sciences 4(2): 96-101.

25. Noh GO, Park KS (2019) Effects of aroma self-foot reflexology on peripheral neuropathy, peripheral skin temperature, anxiety, and depression in gynecologic cancer patients undergoing chemotherapy: A randomised controlled trial. European Journal of Oncology Nursing 42: 82-89.

26. Wanchai A, Armer JM (2019) A systematic review association of reflexology in managing symptoms and side effects of breast cancer treatment. Complementary Therapies in Clinical Practice 38: 101074.

27. Whatley J, Street R, Kay S (2018) Experiences of breast cancer related lymphoedema and the use of reflexology for managing swelling: A qualitative study. Complementary therapies in clinical practice 32: 123129.

$\begin{array}{ll}\text { BIOMEDICAL } & \text { Assets of Publishing with us } \\ \text { RESEARCHES } & \text { - Global archiving of articles } \\ & \text { - Immediate, unrestricted online access } \\ & \text { - Rigorous Peer Review Process } \\ & \end{array}$

